\title{
La razón y el corazón en los muy platicados tiempos del cólera: oralidad, modernidad y medios. A tres caídas sin límite de tiempo
}

Jorge A. González Universidad de Colima

\section{Al mal paso, darle Gerber ${ }^{\mathrm{TM}}$}

ENESTOS precisos tiempos, de cólera e intentos de integración latinoamericana, de apertura y liberación económica en los que se han desmoronado más certidumbres que las que pudimos creer que alguna vez soportaríamos, las relaciones entre oralidad y modernidad dentro del contexto de los medios de comunicación nos pueden proporcionar un buen pretexto para la reflexión sobre algunas particularidades de nuestras culturas contemporáneas.

Comenzaremos por algunas distinciones y relaciones que de suyo suelen coexistir en santa paz, seriamente parecida a la de los sepulcros.

\section{Oral, popular, moderno:}

\section{sugerencias para un menú indigesto}

A estas alturas del partido, una idea errónea es tratar de oponer la cultura oral con la modemidad. Diversas actitudes y concepciones normativas rondan la cuestión de lo oral, en la medida en que suele casi siempre conectarse lo oral con lo popular, y allí tenemos dos problemas.

Por una parte, pocas cosas tan resbaladizas y acomodaticias como la noción de popular. Para los románticos, la pureza está en lo que el pucblo (sincero, genuino, inocente, elemental, etcétera) dice, por tanto su expresión (en este caso la oral) es "mejor" y es "buena" precisamente porque a través de ella se puede atisbar el "alma" del pueblo, los basamentos originales de la nación.

Los anticuarios prefieren lo popular en la medida en que se atenga a ciertas originalidades de rasgos manifiestos. Lo popular hay que conservarlo (hacerlo 
literalmente "conserva") siempre y cuando no se haya contaminado por la cultura industrial, urbana, masificada, inmaculada de la "modernidad" pues.

Los populistas, dentro de una variante más izquierdosa que los románticos, consideran que lo popular es igual a lo revolucionario, es decir no sólo es bueno, sino que es $L a$ verdad que liberará a toda la humanidad, pues finalmente ellos (el pueblo) tienen la razón.

Otros más "modernos" y exclusivistas quisieran que si bien no desapareciera, por lo menos se mantuviera restringido a ciertos ámbitos sociales o culturales. Lo oral es sinónimo de lo tradicional, lo atrasado, lo pobre, lo primario, lo simple, etcétera.

Si recordamos diversas aportaciones para ubicar la noción de popular, sabemos que no se le define como una inmortal esencia, sino como un hecho social e históricamente generado, no se identifica por sus originales y típicos contenidos o substancias, sino como una posición relacional, no se resalta por su origen sino por el uso social que de ello hagan las clases sociales explotadas, dominadas, subalternas y o alternas que genéricamente llamamos pueblo (González, 1990).

Si hablar así nomás de Cultura Popular parece entonces impreciso (mejor sería cuando menos nombrarla en plural) hablar de una cultura oral me parece no sólo impreciso sino también excesivo para lo oral y restrictivo para lo cultural.

Toda forma de expresión oral es cultural, pero ciertamente no toda forma de expresión cultural es oral.

Convendría mejor situar la oralidad como una forma de expresar, transmitir, y acumular la información y la memoria que se consideran socialmente relevantes.

Concedamos que es una forma de primer orden comparada con la permanencia en el tiempo, la capacidad de almacenamiento y la velocidad de acceso de otras formas decididamente más sofisticadas y "modernas", desde la escritura hasta las nuevas formas de grabación óptica, pero ello no le confiere fatalmente ninguna carga negativa ni positiva a priori.

\section{De la oralidad de las culturas o la madre de todas las botellas}

De entrada podemos plantear, con la balanza de la obviedad de nuestro lado que la comunicación oral tiene varias y particulares características (Beduschi, 1990): 
a) Repetibilidad o redundancia. La temporalidad efímera del texto oral, que se acaba, se agota apenas se ha enunciado, dicho o escuchado, requiere de formas recurrentes de repetición, algunas métricas y otras mnémicas. La fidelidad del contenido de la información dependerá inicialmente de la eficacia de las fórmulas para su conservación y transmisión. Justo como en el saber esotérico.

b) Destinatario efectivamente presente. Lo que el buen Mc Luhan nos decía sobre los medios calientes se aplica perfectamente a este caso. La voz es antes que información, expresión y presencia. Estamos en el terreno de la comunicación cara a cara.

c) Proxémica o gestualidad. En la medida en que se está presente, no sólo el hablar, sino la presencia física, gestual acompaña y acompasa, contrapuntea y resalta en diversos planos y volúmenes lo que se dice. Es entonces inseparable el gesto de la palabra (Leroi-Gourham, 1977), al charlar con otro oímos, vemos y sentimos.

d) Interacción dialógica. Es aquella en la que los roles de emisor y receptor se intercambian constantemente.

e) Realización diasistémica. La "lectura" del texto oral depende de una mediación entre el sistema del texto y el sistema del interlocutor. De esta manera la lectura del texto oral en tanto que enunciado, es claramente una nueva enunciación que genera un nuevo enunciado que a su vez será la materia inicial de otra nueva enunciación y así diciendo.

f) Valor determinado por una situación extralingüística. Lo que se dice está marcado y limitado por dos tipos de competencias: una propiamente lingüística, es decir, por el saber para construir frases inteligibles en la lengua usada y una competencia cultural o situacional, que estriba en el saber cuándo, cómo y dónde hablar. De tal manera que no hay competencia "libre" sino siempre sujeta y normada por una situación que está definida en primera instancia por el tipo de espacio social (Bourdieu, 1989) en el que se desarrolla. Más adelante hablaremos de la cultura.

Todo lo oral es cultural, pero no al revés. La expresión oral es elementalmente humana, no puede ser patrimonio exclusivo de ninguna clase, grupo, género o facción. 
Es al mismo tiempo el efecto de una violencia física, pues para hablar se debe aprender a forzar varios órganos que no sólo tienen la función especializada de hablar, sino otras todavía más primarias: respirar, comer, etc. Funda, dentro de las cuatro acciones históricas de base que mencionan Marx y Engels en La Ideología Alemana (Cirese, 1986a), la necesidad asociativa y está en directa relación con la producción y el ejercicio cotidiano del lenguaje.

La expresión oral antecede obviamente a la modernidad, le ha acompañado y con toda seguridad le trascenderá. La pomposa entrada de la modernidad a la escena del mundo no termina con la oralidad, ambas coexisten coyunturalmente (lo efímero en este caso es precisamente el sentimiento de lo moderno, mientras que lo duradero es la forma elementalmente humana de expresión que constituye la oralidad).

\section{De la modernidad y parientes que la acompañan}

La modernidad, producto histórico que surge como una respuesta a los rígidos patrones de la tradición burguesa, nos marca el principio del fin de la concepción de lo sagrado, introduce el principio de secularización de la vida social que durante siglos había girado en torno de fuerzas ocultas, numinosas y designios meta-sociales. En el campo del arte, la modernidad puso el dedo en la llaga por lo menos en tres áreas (Alexander y Seideman, 1990):

a) La autonomía de la estética sobre las normas morales.

b) Valoración de lo nuevo y lo experimental sobre lo antiguo y lo conocido. De paso termina con la mímesis como principio rector del arte.

c) Predominio del individuo, como ser único, irrepetible y original como piedra angular del juicio cultural.

En el aspecto científico, la certeza filosófica de la razón sobre la revelación, tuvo un efecto potenciador enorme que desembocó en el positivismo y en una actitud de búsqueda incesante de explicaciones racionales o al menos racionalmente orientadas. Es en esa vorágine en la que se insertan los desarrollos tecnológicos que hicieron - con el registro mecánico de las palabras y las imágenes - pasar ( Gavanzar?) en menos de 100 años lo que la humanidad había tardado cualquier milenio para intervenir: la palabra. Los pasos de la expresión oral a la escrita, del 
registro de la palabra en el fonógrafo, su transmisión potenciada por la radio y junto con ésta al primer registro de las imágenes (fotografía, cine mudo) implican un gran salto cualitativo y cuantitativo. El desarrollo de la radio otorga la posibilidad de llegar con la voz y con efectos sonoros por primera vez a millones de personas de manera simultánea, pero cuando se logran registrar la imagen y el sonido, unidos simultáneamente, la relación con los públicos cambió de manera radical. Bien lo sabemos que el cine sonoro y posteriormente la televisión canalizaron toda esa energía. Las mezclas que hoy en día encontramos unidas alrededor de la pantalla televisiva (cine/video y video casero), la pantalla y los microprocesadores (Nintendo, Intellivision, Sega, Atari, etc.), las computadoras caseras, y los sistemas láser de impresión, de visión y de audición, dan una versatilidad y una potencialidad para almacenar información en el seno de casi cualquier hogar, como nunca antes jamás la humanidad tuvo durante milenios acceso o siquiera la posibilidad (Levy y Günter, 1988). Otro caso es la capacidad de procesamiento y la posibilidad de no sólo ser usuarios "felices" de tecnologías "transparentes" y "amables", sino de domesticar esas tecnologías y saberes "modernos" para nuestro servicio y dentro de nuestras propias perspectivas.

Por ejemplo, en Comala, pueblo agrícola de 9,000 habitantes del estado de Colima, 36 familias en menos de 280 días rentaron el equivalente a 9,300 horas de videogramas, esto es cerca de un año y tres meses viendo películas de gringos balanceándose de tiempo corrido. Uno sola familia rentó 620 horas de ficción en el mismo período, algo así como un mes completo del año de tiempo de película (González, 1994). Ciertamente, el hecho de que las hayan rentado no nos dice nada acerca de cómo fueron vistas o atendidas esas tantas películas.

Por último, señalo que muchas veces cuando se habla de modernidad en nuestros países, suele hacerse de manera demasiado "primermundista", es decir, con el corazón y la cabeza mamando la crisis de la razón europea o anglosajona, que ignora por completo que nuestros países y en último caso nuestros pueblos, han comenzado a pasar de la premodernidad a la posmodernidad sin transitar siquiera por la cacareada modernidad.

Miles de campesinos prácticamente analfabetas apenas una generación atrás llenan hoy en día los cursos relámpago de computación y programación (Cirese, 1986b).

Si una película como $E l$ Exorcista causó terror, furor y revuelo en muchos países, por lo menos en México y en Brasil, donde la sensualidad de la vida diaria y la 
diferencia entre magia y realidad es "razonable", entre la vida y la muerte no es tan nítida, la película resultaba de un humor involuntario delirante. Curiosa inversión: los intelectuales latinoamericanos con el alma hipotecada a Europa juzgan con esas mismas categorías la películas y los melodramas donde nuestros pueblos lloran, gritan, se agitan. ¿Será la modernidad, o la posmodernidad ? ¿O ninguna de ellas? ¿O todas juntas?

\section{Escape a la oralidad desde el tobogán de la modernidad}

Definitivamente, la expresión oral no puede entonces oponerse a modernidad. Esto significa que hay una oralidad moderna, en la medida que la modernidad es una modalidad de racionalización y especialización de la cultura, en cualquier forma que ésta se manifieste, sea oral, escrita, grabada, etc.

Las formas de expresión oral suelen ser clasificables inicialmente como se presentan en el cuadro 1 (Cirese y Serafini, 1975).

Cuadro 1. Formas de expresion oral

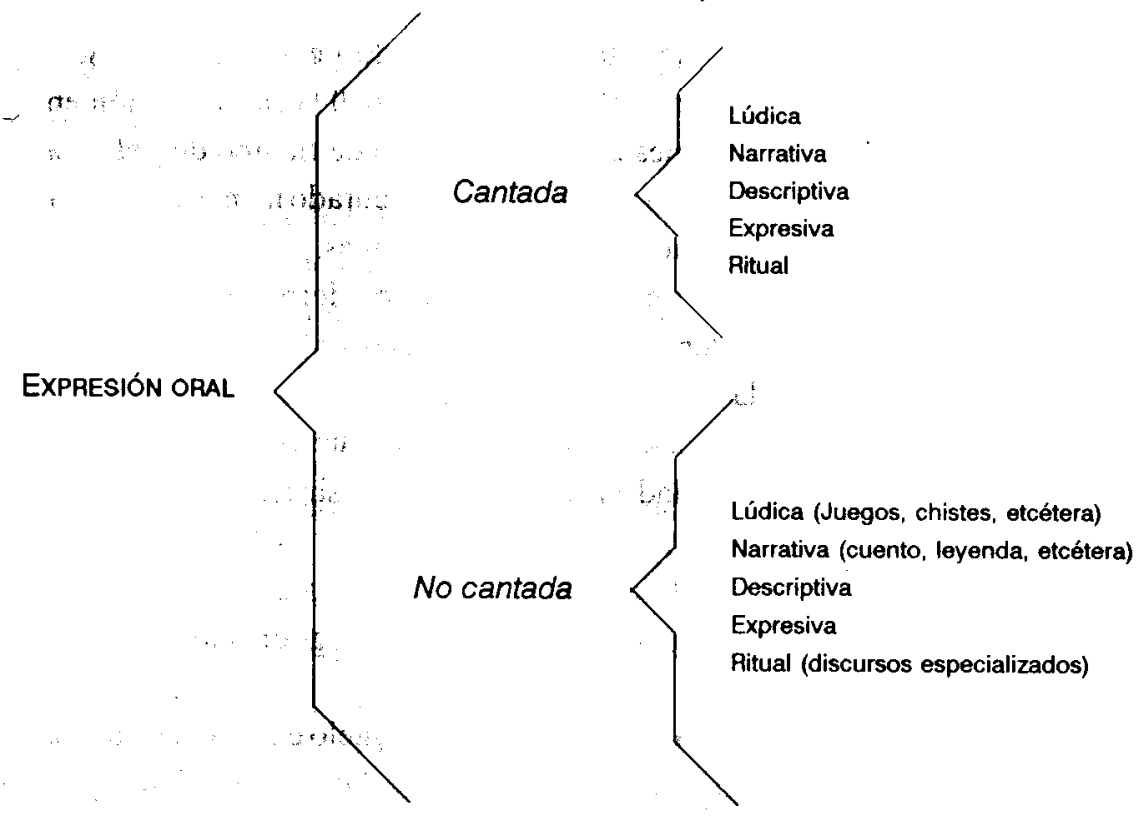


Con esta provisoria clasificación, podemos ubicar un tipo de oralidad de primer orden de carácter situacional y contextual que sin embargo tiene que hacer las cuentas precisamente con otro tipo de oralidad, de segundo orden, industrial y organizacionalmente producida, que tiene la doble cualidad de ser simultáneamente una mercancía y un producto que está hecho precisamente para significar. El punto de encuentro de estos dos órdenes es precisamente un mercado de bienes culturales en el que se entrecruzan determinaciones específicas de la producción y difusión con estrategias diferenciales de fruición y goce de productos culturales (Bourdieu, 1988), que dentro de la modalización de la modernidad han adquirido progresivamente autonomía y especialización crecientes ${ }^{1}$ paralelamente a creaciones de la vida y del mundo (Fossaert, 1983).

De este modo resulta que el modernismo en nuestros países no es la expresión pura de la racionalización económica, sino el modo en que los grupos dirigentes dominantes se "hacen cargo de la intersección de diferentes temporalidades históricas y tratan de elaborar con ellas un proyecto común" (García Canclini, 1990:71).

La modernidad en nuestros países no sustituyó simplemente lo viejo por lo nuevo ni lo tradicional por lo moderno, sino que en el arreglo con la densidad de nuestras culturas profundas (Bonfil Batalla, 1990), su propia historia ha creado formaciones culturales complejas, heterogéneas y multitemporales que resuellan simultáneamente en nuestras culturas.

Dentro de este marco que venimos presentando, conviene preguntarse porqué los productos más exitosos (comercial y culturalmente) de nuestras organizaciones industriales de la cultura y particularmente de los medios de difusión colectiva suelen ser textos complejos a dominancia oral. En el caso de las fotonovelas, los comics, las radionovelas, las telenovelas, los melodramas cinematográficos, los corridos, los tangos.

Todos ellos y particularmente el melodrama televisivo (González, 1993) presentan una serie de características y de degustación y lectura "dialógica" (Lotman, 1980), en tanto que actividad ligada necesariamente a una memoria por parte del público, que conectan directamente con las formas de ejercicio cotidiano de la realidad. ¿Es entonces que estos "exitosos" y complejos textos permiten más "dialoguicidad" (válganos el recontra barbarismo) que otros?

1 Para el caso de Brasil puede consultarse la excelente obra de Renato Ortiz (1988). 
Esta cualidad de progresiva irrupción de los lectores en los textos (que precisamente por ser codificados, producidos y dirigidos desde una organización de especialistas, parecía tener cancelado todo intento de transgresión del sentido "original", del modo indicado más arriba, es dècir, en un juego espiral de enunciaciones y nuevas enunciaciones de segundo y enésimo orden, en el que primero está el placer, las tripas, el estómago, el corazón (González, 1990b), bajo la permisiva certidumbre de la memoria, ciertamente hacen explotar cualquier concepción que pretenda oponer las condiciones de lectura y fruición de la oralidad con la modernidad. En estos productos culturales, igual que el texto escrito, anulan la posibilidad de tomar parte en la producción de la enunciación. Todos podemos charlar, pero sólo algunos tienen acceso laboral en Televisa o en Teve Globo. Sin embargo, contienen en su interior una "especialidad" que está deliberadamente destinada a ser ocupada por el lector y si acordamos que no hay lecturas aisladas, sino siempre reticularmente medidas, es decir dentro de redes ideológicas de convivencia elemental, particularmente la familia y los grupos primarios, tenemos pues que estos productos que he llamado dominancia oral, son algo más que el puro texto, y sólo viven en la concreción que depende de las disposiciones que los lectores van aportando en función del propio espacio social en que se ubiquen y en relación directa con la memoria social que se pone en juego con el texto.

Por esa razón se ha planteado la distinción entre culturas textualizadas y gramaticalizadas (Lotman, 1980). La modernidad sin más, ya hace tiempo debería haber acabado con las primeras, sin embargo, éstas siguen tan campantes. ¿Dónde se nos quedaron las masas?

\section{¿La cultura? Lo único que queda cuando ya no queda nada}

Llegamos al último punto que toca a la cultura. No pretendo dar una definición más dentro de las corrientes, sólo voy a mencionar cinco características que me parece que ayudan a comprender mejor estas relaciones medio indigestas y medic tortuosas de las que nos hemos venido platicando desde hace ya un rato.

1) La cultura nos da la posibilidad de adaptamos a la realidad que nos toca vivir. Es nuestra sentido práctico de la viàa y la posibilidad de vivir y sobreviviı en el presente. Es razón y mesura necesaria para poder continuar. 
2) Sin embargo, no sólo es capacidad de adaptarse a la cruda y muchas veces pesada realidad, la cultura es también sueño, fantasía, juego, utopía, exceso yreventón de los mismísimos límites de la vida presente. La cultura estambién la capacidad de imaginar que la vida pudiera ser de otro modo y con ello accedemos a la facultad de crear mundos posibles, reinos de la evasión y la ruptura de barreras, tal vez por el momento, sólo por el momento, irrealizables.

3) La cultura es simultáneamente, raíz y ligadura, evocación incorporada de lo que hemos sido y también de lo que pudimos no ser, memoria viva de nuestros muertos e itinerario reconstruido de nuestros pasos perdidos. Es con ello que damos espesor y densidad al presente y factibilidad fundada al porvenir. Por ello los pueblos que pierden la memoria con ello cancelan la posibilidad de permanecer y trascender.

4) En esta tesitura, la cultura nos proporciona un único instrumental para nombrar y definir la realidad. Para generar representaciones simples o complejas, puras o impuras, de la vida y del mundo, donde en diferentes composiciones y pesos específicos se amalgaman y declaran las certidumbres y las incertidumbres del presente, del futuro y del pasado. Con ellas se modera y se modula nuestro sentido del estar, del ser, del hacer, del poder y del parecer. Tanto en su liga con la memoria como con el futuro.

5) Y como no hay definición que no se realice desde un lugar, con una perspectiva y dentro de ciertos intereses, es decir, porque toda visión del mundo es una división del mundo, resulta que la cultura es constitutivamente el terreno en que se lucha, precisamente por negociar e imponer un principio ordenador de las dimensiones abordadas. Luchas que pueden ser intermitentes para expandir o para comprimir el espacio global del discurso social común, el sentido de lo que necesitamos de quiénes somos y qué es lo valioso en esta vida. Valores, identidades y necesidades que giran en torno de formaciones culturales transclasistas, que antes que ser esencias inmutables (La raza, el amor, la dicha, los sexos, la ecología, la numinosidad, la diversión, la Patria y la Matria, la Nación, la región, la salud y precisamente la modernidad), constituyen arenas de lucha, frentes culturales en los que se juegan - como en los gallos, como en la lucha libre - las apuestas por el "verdadero" sentido de las cosas (González, 1994). 
Y es que, en esa encolerizada lucha, las modernas modalidades de la palabra y de la oralidad también tienen su corazoncito.

\section{Referencias bibliográficas}

AleXANDer J. y S. Seideman (Eds.) (1990): Culture and society, Contemporary Debates. Estados Unidos: Cambridge University Press.

BEDUSCHI Lidia (1990): "El texto, la escena. apuntes de semiótica del texto oral". Estudios sobre las culturas contemporáneas, Vol III, Núms. 8 y 9, pp. 339-348. México: Universidad de Colima

BoNFIL Guillermo (1990): México Profundo. Una civilización negada. México: Grijalbo / CNCA.

BOURDIEU Pierre(1988): Aeconomía dastrocas simbolicas.Sao Paulo: Perspectiva.

_ (1989a): Ce que parler veut dire. París: Fayard.

___ (1989b): "El espacio social y la génesis de las clases". Estudios sobre las culturas contemporáneas, Vol.III, Núm. 7, pp. 27-55. México: Universidad de Colima.

(1990): “El mercado lingüístico”. En Sociologíay cultura. México: Grijalbo.

CIRESE A. M. (1986a): "Notas provisorias sobre signicidad, fabrilidad, procreación y primado de las infraestructuras". Estudios sobre las culturas contemporáneas, Vol.1, Núm. 1, pp. 97-148. México: Universidad de Colima.

(1986b): "El poder de la computadora: cómo ordenar a un esclavo que no tiene miedo a la muerte?". Estudios sobre las culturas contemporáneas, Vol. II, Núm. 6, pp. 203-230. México: Universidad de Colima.

- y L. SERAFINI (1975): Tradizioni orali non cantate: primo inventario nazionale pertipi, motivi e argomenti. Roma: Ministerio dei Beni Culturali e ambientali. 
FOSSAERT R. (1983): La societé (VI), Les structures Ideologiques. París: Ed. du Seuil.

GARCÍA CANCLINI Néstor (1990): Culturas híbridas. Estrategias para entrar y salir de la modernidad. México: Grijalbo.

GoNZÁleZ Jorge A. (1990a): Sociología de las culturas subaltemas. Mexicali: Universidad Autónoma de Baja California.

(1990b): "De tripas, cuajo y corazón. Ideas para una historia mínima de los tecno-placeres cotidianos". Documento presentado en el Segundo Congreso Nacional de Historiadores de la Ciencia y la Tecnología, México.

(1993): "El regreso de... La cofradía de las emociones (in ) terminables. Telenovela, memoria, familia." En Néstor GARCía CANCLINI (Ed.) El consumo cultural en México. México: CNCA.

(1994): "Los Frentes Culturales: culturas, mapas, poderes y luchas por las definiciones legítimas de los sentidos sociales de la vida". En Más (+) Culturas(s). Más ensayos sobre realidades plurales. México: SEC/ CNCA, Col. Pensar la cultura.

(1994): "Videotecnología y modernidad por los dominios de Pedro Páramo". En Más(+) Cultura (s). Más ensayos sobre realidades plurales. México: SEC / CNCA, Col. Pensar la cultura.

GOURHAN, Leroi (1977): Il gesto e la parola. 2 tomos. Torino: Einaudi.

LEVY M. y B. GÜNTER (1988): Home video and the changing nature of the television audience. Londres: John Libbey \& IBA.

LOTMAN J.(1980): Testo e contesto, Semiótica dellárte e della cultura . Bari: Lateerza.

ORTIZ Renato (1988): A modema tradiçao brasileira. Cultura brasileira e industria cultural. Sao Paulo: Brasiliense. 